\title{
O político nas relações de sentido: uma análise semântica do termo professor na Lei de Diretrizes e Bases da Educação Nacional n ${ }^{\circ}$ 9.394/96
}

\author{
Lívia Cristina de Souza Sigliani* \\ Adilson Ventura**
}

\begin{abstract}
Resumo: Este trabalho apresenta uma análise dos sentidos do termo professor em excertos selecionados da primeira edição da LDB № 9.394/96. Para tanto, partimos dos pressupostos da Semântica do Acontecimento, teoria semântica enunciativa que considera que a constituição do sentido se dá na enunciação em uma relação do sujeito com a língua, sendo esta relação uma prática política, pois instaura o conflito no centro do dizer. Nosso objetivo é analisar como se configura o político nos sentidos de professor, partindo da hipótese de que há um embate entre sentidos de prestígio e de desvalorização. Os resultados obtidos convalidam nossa hipótese.

Palavras-chave: Semântica do Acontecimento. Sentido. Professor. Político.
\end{abstract}

Abstract: This work presents an analysis of the meanings of the term teacher in excerpts selected from LDB № 9.394/96 first edition. By the assumptions of Semantics of the Event, enunciative semantic theory that considers the constitution of meaning occurs in the enunciation in a relation of the subject with the language: a political practice: because it establishes the conflict in the center of the saying. Our objective is to analyze how the politician is configured in the teacher's sense, starting from the hypothesis that there is a clash between prestige and devaluation senses. The results obtained validate our hypothesis.

Key-words: Semantics of event. Meaning. Teacher. Politics.

Resumen: Este trabajo presenta un análisis de los significados del término docente en extractos seleccionados de LDB № 9.394 / 96 primera edición. Basado en la Semántica del Acontecimiento, la teoría semántica enunciativa que considera la constitución del significadoocurre en la enunciación en una relación del sujeto con el lenguaje: una práctica política:porque establece el conflicto en el centro del dicho. Nuestro objetivo es analizar cómo seconfigura el político en el sentido del maestro, a partir de la hipótesis de que existe un choque entre los sentidos de prestigio y devaluación. Los resultados obtenidos validannuestra hipótesis.

Palabras clave: Semánticadel evento. Sentido. Profesor. Política.

\footnotetext{
Mestranda em Linguística pela Universidade Estadual do Sudoeste da Bahia (UESB). http://orcid.org/o0oo-0002-4292-2711

${ }^{* *}$ Professor Adjunto da Universidade Estadual Sudoeste da Bahia (UESB) e dos Programas: Pós Graduação em Linguística e Mestrado Profissional em Letras da UESB. http://orcid.org/oooo-0001-7521-3981
} 


\section{Considerações iniciais}

Ao investigarmos os sentidos de professor em materialidades significantes no âmbito jurídico, na mídia e no marketing, notamos que, embora sentidos de valorização e reconhecimento estejam presentes, sentidos de desprestígio ou de desvalorização profissional também são comumente percebidos. Em vista disso, analisar esses sentidos é o objetivo de um trabalho de maior fôlego, no caso, nossa pesquisa de mestrado já em andamento. Para este trabalho, apresentaremos a análise de parte dos excertos que compõe a materialidade jurídica do corpus de nossa pesquisa.

Sendo assim, partindo dos trabalhos de Lagazzi (2007), pensamos a materialidade significante não enquanto algo simplesmente no mundo, mas como algo no mundo que significa a partir de sua relação com o simbólico. Ou seja, por meio do trabalho do simbólico, as materialidades produzem diferentes significações em cada enunciação específica, visto que essas significações são tomadas na História. Dessa forma, cada materialidade possui uma especificidade em sua forma de significar, o que nos leva ao interesse geral de analisar diferentes materialidades.

Conforme a teoria da Análise de Discurso, Orlandi (2002), o indivíduo é interpelado em sujeito pela ideologia em um processo simbólico determinado pelo modo como terá sua forma individualizada na história. No caso da sociedade capitalista, um indivíduo livre de coerções responde como sujeito de direito e deveres, como sujeito jurídico. Sendo o professor um sujeito jurídico e considerando a importância da Lei de Diretrizes e Bases da Educação Nacional n 9.394 (BRASIL, 1996) como lei que define e regulamenta o sistema educacional brasileiro, nosso propósito neste artigo é o de analisar os sentidos de professor em parte do corpus, ou seja, em recortes da primeira versão, mais especificamente, em excertos do TÍTULO VI Dos profissionais da educação. Ancorados nos pressupostos da Semântica do Acontecimento, objetivamos analisar quais designações configuram nosso recorte e de que maneira o político é observado nas relações de sentido que compõem a materialidade em questão. 
A Lei de Diretrizes e Bases da Educação Nacional n 9.394, doravante LDB № 9.394/96, sancionada pelo então presidente da república Fernando Henrique Cardoso, em 20 de dezembro de 1996, e alicerçada nos princípios da Constituição Nacional de 1988, visa a definir e regulamentar as bases da educação brasileira. Desde sua promulgação, tem passado por diversas alterações mediante as mudanças ocorridas na lei ao longo dos anos (CONCLI, 2017). O que nos chamou atenção para a pertinência de analisar excertos da primeira edição da LDB № 9.394/96, foi o fato de que nesta edição há 12 ocorrências do termo professor ao longo do texto, entretanto, no TÍTULO VI Dos profissionais da educação, que trata das questões relacionadas à formação e à valorização profissional do professor, o termo está ausente. Somente na atualização do ano de 2009, o termo professor foi inserido no TÍTULO VI Dos profissionais da educação (BRASIL, 2009).

A fim de fundamentarmos nossa análise e discussão dos sentidos de professor na LDB № 9.394/96, lançaremos mão da teoria da Semântica do Acontecimento, teoria semântica enunciativa proposta pelo professor da Unicamp Eduardo Guimarães (2002, 2007, 2009, 2011, 2018), que parte do pressuposto da não transparência da língua e que o sentido se dá na enunciação, no acontecimento do dizer. Para a Semântica do Acontecimento, os sentidos são constituídos numa relação da língua com a própria língua, sendo que essa relação é tomada na História. A enunciação consiste em uma relação do sujeito com a língua, sendo uma prática política, pois instaura o conflito no centro do dizer. A perspectiva teórica da Semântica do Acontecimento vem sendo desenvolvida por estudiosos em grupos de pesquisa pelo Brasil, inclusive na UESB Universidade Estadual do Sudoeste da Bahia, onde trabalhos de grande relevância são desenvolvidos pelo GEPES (Grupo de Estudos e Pesquisa em Semântica), que trabalha com a análise da constituição de sentidos de diversos termos, em diferentes fatos de linguagem, em materialidades diversas como livros didáticos, leis, mídia, mapas, mídias digitais, entre outros.

Para empreendermos nossa análise, além de mobilizarmos os pressupostos citados acima, serão executados os procedimentos de análise próprios da teoria, que são a reescrituração e a articulação e para representarmos como se configuram essas relações 
de sentido, apresentamos a configuração do Domínio Semântico de Determinação (DSD), como demonstraremos na próxima seção.

\section{Semântica do Acontecimento: teoria e procedimentos enunciativos}

Para que possamos analisar os sentidos de professor no TÍTULO VI Dos Profissionais da Educação na LDB № 9.394/96, nos nortearemos pelos pressupostos teóricos da Semântica do Acontecimento e por seus procedimentos enunciativos de análise: a reescrituração e a articulação. A Semântica do Acontecimento, doravante SA, teoria semântica enunciativa proposta por Guimarães (2002, 2007, 2009, 2011,2018) considera: "[...] o enunciado como unidade semântica de análise, definida por sua relação de integração ao texto" (GUIMARÃES, 2018, p.8). Em outras palavras, para a SA o texto é uma dispersão de sentidos, pois é na enunciação que os sentidos são constituídos e o enunciado, por sua vez, é tratado como integrado a um texto, como veremos mais adiante neste artigo. Para compreendermos como esses sentidos são constituídos, vale ressaltar que a SA coloca de saída a questão do sujeito que enuncia, pois parte dos pressupostos da opacidade da língua e do sujeito. Isto quer dizer que a língua não é transparente e sua relação com o real é histórica. Nessa perspectiva, o sujeito também não é transparente e não possui controle algum sobre os sentidos, uma vez que, em nosso escopo teórico, o sujeito não sendo origem do sentido é tomado por ele e é agenciado a dizer o que diz pelo espaço de enunciação: "O Locutor só é Locutor enquanto falante determinado por este espaço político do dizer, o espaço de enunciação" (GUIMARÃES, 2009, p.50). Deste modo, a enunciação, enquanto acontecimento da linguagem constitui-se em uma relação do sujeito com a língua, sendo essa relação uma prática política, pois instaura o conflito no centro do dizer (GUIMARÃES, 2002, p.8).

Um conceito fundamental da SA que mobilizaremos em nossa análise é o conceito de político. Para que possamos compreendê-lo é importante termos em mente que o acontecimento de linguagem se dá no espaço de enunciação, conceito que Guimarães apresenta como: “[...] um espaço regulado e de disputas pela palavra e pelas línguas, enquanto espaço político" (GUIMARÃES, 2002, p. 18), isto é, corresponde a um 
espaço de relação entre línguas e falantes, sendo esse espaço caracterizado por uma disputa incessante pela língua numa relação de inclusão/exclusão, posto que essa divisão política nunca é estanque, pois há uma busca constante pelo direito de falar. Assim sendo, o falante tomado pelo espaço de enunciação é agenciado a falar. Deste modo, podemos dizer, então, que a enunciação nada tem a ver com a intenção do sujeito que enuncia, visto que o acontecimento de linguagem agencia o sujeito a dizer o que diz e, ao tratarmos dessa questão, devemos considerar além das relações de linguagem, elementos como o lugar social e a História (GUIMARÃES, 2018, p.45).

Outro conceito basilar da teoria de Guimarães é o de temporalidade. Como já discutido, o sentido se dá no acontecimento em uma relação entre língua e sujeito permeada pelo conflito. Não obstante, para que isso ocorra, é instaurada pela enunciação uma temporalidade que é diferente de uma temporalidade cronológica ou de uma temporalidade instaurada pelo sujeito. $\mathrm{O}$ acontecimento instaura sua própria temporalidade. No acontecimento de linguagem a enunciação instaura um presente e, para constituir sentido, a partir das relações de linguagem contidas no enunciado, remete a um memorável que não é formado por lembranças pessoais, mas por enunciações passadas. Essas memórias de sentidos de enunciações passadas são projetadas para o futuro, ou seja, para possíveis interpretações:

A temporalidade do acontecimento constitui o seu presente e um depois que abre o lugar dos sentidos, e um passado que não é lembrança ou recordação pessoal de fatos anteriores. O passado é, no acontecimento, rememoração de enunciações passadas, ou seja, se dá como parte de uma nova temporalização, tal como a latência de futuro [...] o acontecimento é sempre uma nova temporalização, um novo espaço de conviviabilidade de tempos, sem a qual não há sentido, não há acontecimento de linguagem, não há enunciação (GUIMARÃES, 2002, p. 12).

No que concerne à análise da constituição dos sentidos, a SA faz um deslocamento do conceito de integratividade de Benveniste (1976, p. 134-135). Esse deslocamento de integratividade implica em analisar o sentido de uma expressão linguística não de maneira segmental, mas enquanto integrado a um enunciado e o enunciado enquanto parte de um texto: “[...] consideramos que o sentido de um enunciado é sua relação de integração ao texto em que está” (GUIMARÃES, 2018, p.42). Isto quer dizer que o enunciado não é tomado isoladamente ou como um processo 
somatório, mas como lugar de observação da palavra em relação ao texto. Para analisar o sentido de um enunciado de forma integrativa, a SA propõe dois procedimentos enunciativos: a articulação e a reescrituração.

A articulação corresponde a "[...] uma relação de contiguidade significada pela enunciação" (GUIMARÃES, 2009, p. 51). Na articulação são percebidas relações de predicação e complementação - relação determinante/determinado (GUIMARÃES, 2018, p. 8o). A articulação pode acontecer de três modos distintos: 1) por dependência, quando os elementos contíguos se organizam por uma relação que constitui no conjunto um só elemento; 2) por coordenação, quando se apresenta por um processo de acúmulo de elementos numa relação de contiguidade;3) por incidência, quando há relação entre um elemento e outro sem uma relação de dependência estabelecida (GUIMARÃES, 2009, p. 51). Já as relações de reescrituração são definidas pela maneira como um termo é redito insistentemente em um texto de forma diferente de si. Contudo, diferentemente das relações de articulação, as relações de reescritura não necessariamente são de contiguidade, podendo acontecer entre elementos à distância dentro do texto:

\begin{abstract}
A reescrituração é o procedimento pelo qual a enunciação de um texto rediz insistentemente o que já foi dito fazendo interpretar uma forma como diferente de si. Este procedimento atribui (predica) algo ao reescriturado. Esta reescrituração é o procedimento que coloca em funcionamento uma operação enunciativa fundamental na constituição do sentido de um texto (GUIMARÃES, 2007, p. 84).
\end{abstract}

As relações de reescrituração podem ser: a) por repetição, quando a expressão ou o termo é dito repetidamente, na íntegra, no texto; b) por substituição, quando a expressão ou termo é retomado no texto por outra expressão ou termo; c) por elipse, quando a expressão ou termo é omitido em alguma parte do texto; d) por expansão, quando uma expressão ou termo tem seu sentido ampliado por outra expressão ou termo no texto; e) por condensação, ao contrário da reescritura por expansão, ocorre quando uma expressão ou termo é resumido por outra expressão ou termo; f) por definição, quando uma expressão ou termo são definidos por outro termo ou expressão ao longo do texto.

As diversas formas de reescrituração podem produzir as seguintes relações de sentido: a) sinonímia, quando a reescrituração apresenta uma palavra ou expressão 
como tendo o mesmo sentido que a outra à qual se liga; b) especificação, quando atribui elementos de sentido ao reescriturado pela expressão que o reescritura; c) desenvolvimento, quando produz um desenvolvimento do sentido da expressão ou termo reescriturado; d) globalização ou totalização, quando o reescriturado determina generalizações; e) enumeração, lista os termos, os enumera, não necessariamente de forma somatória; f) definição, quando estabelece uma relação de definição entre a reescrituração e o reescriturado (GUIMARÃES, 2018, p.90-93).

Por fim, para representar a análise das relações de reescritura e articulação aqui abordadas, temos o DSD (Domínio Semântico de Determinação) que se caracteriza por “[...] uma interpretação do próprio processo de análise e deve ser capaz de explicar o funcionamento do sentido da palavra no corpus especificado" (GUIMARÃES, 2007, p. 81). Essas relações de sentido são demonstradas por meio de representações gráficas, por sinais específicos propostos por Guimarães, como veremos na seção a seguir.

\section{Análise dos sentidos de professor na LDB № 9·394/96: resultados e discussões}

Antes de iniciarmos a análise propriamente dita, importa explicar como as materialidades analisadas foram selecionadas. Como dito anteriormente, a SA parte do pressuposto do enunciado enquanto parte de um texto e, para isso, é necessário um

procedimento de análise apropriado, como bem apontado por Guimarães, que toma como procedimento de trabalho a sondagem.

A sondagem compreende um modo de "eleger" enunciados a serem estudados a partir de uma pergunta. No caso, temos duas perguntas a serem respondidas neste trabalho:

a) Quais os sentidos de professor na LDB № 9.394/96?

b) Como se configura o político nas relações de sentido ao analisarmos o termo professor?

A partir das perguntas, o procedimento de sondagem tem a finalidade de encontrar um enunciado em um recorte do acontecimento de enunciação e, assim, explorar esse enunciado enquanto elemento deste recorte e enquanto integrado ao texto, 
considerando que recorte para a Semântica do Acontecimento é um fragmento do acontecimento da enunciação: "Pelo recorte as formas linguísticas aparecem como correlacionadas em virtude de terem a mesma relação com o acontecimento, independente da posição na sequência” (GUIMARÃES, 2018, p.75-76).

Para realizarmos nossa análise, selecionamos por meio do procedimento de sondagem,o TÍTULO VI Dos Profissionais da Educação na LDB № 9·394/96, que contém 67 artigos. Nossa análise será realizada por cada artigo e dividida da seguinte maneira: 1) Formação dos profissionais da educação; 2) Docentes para atuar na educação básica; 3) Formação de profissionais da educação dos diversos níveis; 4) Atuação fora da sala de aula; 5) Estágio; 6) Exercício do magistério superior; 7) Valorização dos profissionais da educação. Isto posto, seguimos a desenvolver a análise dos artigos e seus respectivos DSDs:

1) Formação dos profissionais da educação:

Art. 61. A formação de profissionais da educação, de modo a atender aos objetivos dos diferentes níveis e modalidades de ensino e às características de cada fase do desenvolvimento do educando, terá como fundamentos:

I - a associação entre teorias e práticas, inclusive mediante a capacitação em serviço;

II - aproveitamento da formação e experiências anteriores em instituições de ensino e outras atividades (BRASIL, 1996, grifo nosso).

No recorte analisado do artigo 61, embora o termo professor não esteja presente no excerto, podemos observar por meio do procedimento enunciativo de reescrituração, que o termo "profissionais da educação", é uma reescritura por substituição do termo professor, o que produz, desse modo, uma relação de especificação, pois o enunciado diz respeito a um tipo específico de profissional, no caso, o profissional da educação. Além de especificar, também estabelece uma definição, sendo que professor é um profissional da educação. Observa-se, também, que essa reescritura está articulada por coordenação ao termo "formação", que por sua vez, se articula por coordenação às expressões: "de modo a atender aos objetivos dos diferentes níveis e modalidades de ensino e às características de cada fase do desenvolvimento do educando”. Isto quer dizer que o artigo analisado trata de questões relacionadas à formação do professor. Para uma melhor 
compreensão de como se dão essas relações de sentido, vejamos a seguir como os sentidos são constituídos no enunciado através do DSD:

Quadro 1 - DSD de profissionais da educação

$$
\text { formação †profissionais da educação }
$$

Fonte: elaboração própria (Utiliza-se os caracteres $(-, \perp, \uparrow,-$,$) para representar as relações de$ determinação; o sinal [--] significa sinonímia; o sinal [-]significa antonímia).

Nas relações de sentido demonstradas no DSD, o termo "profissionais da educação" é determinado por "formação". A seguir, vejamos em um segundo DSD como se dão os sentidos de formação:

Quadro 2 - DSD de formação

alcançar os objetivos dos níveis e modalidades de ensino

$\perp$

formação

$\mathrm{T}$

atender às demandas do educando

Fonte: elaboração própria (Utiliza-se os caracteres $(-, \perp, \top,-$, ) para representar as relações de determinação; o sinal [--] significa sinonímia; o sinal [-]significa antonímia).

Nas relações representadas pelo DSD, o termo formação é determinado pela expressão alcançar os objetivos dos níveis e modalidades de ensino e por atender às demandas do educando, isto é, essas relações enunciativas constituem sentidos de como deve ser a formação de um professor. Sendo assim, mediante a observação da constituição de sentidos ao longo da análise, podemos interpretar que o professor deve ter uma formação abrangente, que assegure conhecimentos que lhe permitam alcançar os objetivos dos diversos níveis e modalidades de ensino e que o faça atender às demandas de cada fase de desenvolvimento do aluno. 
2) Docentes para atuar na educação básica:

Art. 62. A formação de docentes para atuar na educação básica far-se-á em nível superior, em curso de licenciatura, de graduação plena, em universidades e institutos superiores de educação, admitida, como formação mínima para o exercício do magistério na educação infantil e nas quatro primeiras séries do ensino fundamental, a oferecida em nível médio, na modalidade Normal (BRASIL, 1996, grifo nosso).

No artigo 62, professor é reescriturado por expansão pela expressão "docentes para atuar na educação básica”, o que gera uma relação de especificação, pois o docente tratado pelo enunciado é aquele que atua na educação básica. Concomitantemente, essa reescrituração mantém uma relação de articulação por coordenação ao termo formação que, por seu turno, articula-se aos termos "nível superior" e "cursos de licenciatura”. Tais relações de linguagem remetem ao sentido deque a formação do professor deve ser acadêmica, em cursos específicos para o exercício de sua função, ou seja, formação em nível superior, em cursos de licenciatura, como demonstrado no DSD abaixo:

Quadro 3 - DSD de docentes para atuar na educação básica

\begin{tabular}{|c|c|c|}
\hline & ível superior & \\
\hline docentes para atuar na educação básica & formação & - licenciatura \\
\hline
\end{tabular}

Fonte: elaboração própria (Utiliza-se os caracteres $(-, \perp, T,+$,$) para representar as relações de$ determinação; o sinal [-- ] significa sinonímia; o sinal [- ]significa antonímia)

Neste DSD, Nível superior determina formação, enquanto que este determina docentes para atuar na educação básica e licenciatura. Essas relações enunciativas instauram o sentido de que, para ministrar aulas na educação básica, o professor deve ter formação específica, melhor dizendo, em curso superior de licenciatura.

Dando continuidade à análise do enunciado, nota-se, entretanto, que o termo “admitida" está articulado por incidência às expressões: "como formação mínima" e a “oferecida em nível médio", sendo que ambas são reescrituras por expansão do termo formação, ao passo que se articulam por coordenação às expressões: "exercício do magistério na educação infantil e nas quatro primeiras séries do ensino fundamental". As 
relações de linguagem instauradas pelo enunciado nos permitem interpretar que, para lecionar na educação infantil e nos quatro primeiros anos do ensino fundamental, basta o professor ser capacitado em nível médio, na modalidade normal de ensino. Observemos, na sequência, como essas relações se constituem por meio do DSD:

Quadro 4 - DSD de docentes para atuar na educação básica (2)

\begin{tabular}{|c|}
\hline docentes para atuar na educação básica \\
$\qquad$ \\
educação infantil e ensino fundamental I $\quad$-nível médio
\end{tabular}

Fonte: elaboração própria (Utiliza-se os caracteres $(-, \perp, T, F$, ) para representar as relações de determinação; o sinal [--] significa sinonímia; o sinal [-] significa antonímia)

No DSD acima, docentes para atuar na educação básica é determinado por educação infantil e ensino fundamental I que, por sua vez, é determinado por nível médio. Essas relações enunciativas sustentam o sentido de que para o professor lecionar na educação infantil e ensino fundamental I não se exige formação superior, basta, no mínimo, formação em nível médio. O que chama atenção na análise é que a LDB № 9.394/96 considera a educação infantil e as séries iniciais do ensino fundamental como níveis da educação básica, todavia, nesta análise, o enunciado instaura sentidos que educação infantil e as séries iniciais do ensino fundamental são diferentes de educação básica e que demandam menos especialização do professor que leciona nesses níveis.

3) Formação de profissionais da educação dos diversos níveis:

Art. 63. Os institutos superiores de educação manterão:

I - cursos formadores de profissionais para a educação básica, inclusive o curso normal superior, destinado à formação de docentes para a educação infantil e para as primeiras séries do ensino fundamental;

II -programas de formação pedagógica para portadores de diplomas de educação superior que queiram se dedicar à educação básica;

III - programas de educação continuada para os profissionais de educação dos diversos níveis (BRASIL, 1996, grifo nosso).

$\mathrm{Na}$ análise do artigo 63, professor é reescriturado de quatro maneiras. Primeiro, encontramos uma reescritura por expansão pela expressão "profissionais para educação básica”, formando, dessa maneira, uma relação de especificação, visto que a expressão 
além de expandir os sentidos de professor, trata de um profissional específico, o profissional da educação básica. Essa reescritura se relaciona por meio de articulação por coordenação às expressões: “Os institutos superiores de educação manterão” "cursos formadores". Essas relações enunciativas constituem o sentido deque as instituições de educação superior oferecem formação aos professores.

Em seguida, professor é reescriturado por substituição ao termo “docente", produzindo, assim, uma relação de sinonímia à medida que mantém uma articulação por incidência ao termo inclusive, que, por seu turno, se articula por coordenação às expressões: formação, curso normal superior, educação infantil e primeiras séries do ensino fundamental. Essas relações nos possibilitam interpretar que as instituições de ensino superior oferecem formação aos professores, inclusive àqueles que lecionam na educação infantil e nos quatro primeiros anos do ensino fundamental, ou seja, os professores que possuem formação em nível médio. Vejamos essas relações enunciativas no seguinte DSD:

Quadro 5- DSD de formação superior

profissionais para educação básica

丁

formação superior

$\perp$

profissionais para educação infantil e ensino fundamental I

Fonte: elaboração própria (Utiliza-se os caracteres $(\dashv, \perp, \top, F$,$) para representar as relações de$ determinação; o sinal [--] significa sinonímia; o sinal [-] significa antonímia)

No DSD acima, a expressão formação superior determina profissionais para educação básica, ao mesmo tempo em que determina profissionais para educação infantil e ensino fundamental I. Tais relações de linguagem constituem o sentido de que para atuar na educação básica, na educação infantil e no ensino fundamental I é necessária formação específica, ou seja, a formação oferecida pelas instituições de educação superior. Neste recorte podemos notar que, apesar de fazerem parte da educação básica, a educação infantil e o ensino fundamental I são tratados como 
elementos diferentes de educação básica, sustentando, desta forma os sentidos percebidos no DSD 3 .

Na sequência da análise, nota-se que portadores de diplomas de educação superior é uma reescritura de professor por expansão e se articula por coordenação à “formação pedagógica”, enquanto que esta está articulada por dependência à expressão “que queiram se dedicar à educação básica”. Essas relações produzem o sentido deque um profissional portador de diploma de nível superior que queira ser professor na educação básica precisa de formação pedagógica. A representar essas relações de sentido temos o seguinte DSD:

Quadro 6 - DSD de portadores de diplomas de educação superior portadores de diplomas de educação superior

\section{T}

formação pedagógica para atuar na educação básica

Fonte: elaboração própria (Utiliza-se os caracteres $(\dashv, \perp, T, F$, ) para representar as relações de determinação; o sinal [--] significa sinonímia; o sinal [-]significa antonímia)

Neste DSD, portadores de diplomas de educação superior é determinado por formação pedagógica para atuar na educação básica. Tais relações enunciativas nos permitem interpretar que para ser professor na educação básica se faz necessário ter formação específica, e, assim, nos remete ao memorável de profissionais que possuem formação superior em áreas diferentes da área da educação, mas lecionam na educação básica. Para esses profissionais existem programas de formação pedagógica que os qualificam como professores.

Por último, professor é reescriturado por expansão pelo termo: "profissionais de educação dos diversos níveis", o que expande os sentidos de professor ao passo que produz uma generalização, pois trata-se de profissionais de educação dos diversos níveis. Essa reescritura mantém uma articulação por coordenação à expressão "programa de formação continuada", como veremos no DSD a seguir:

Quadro 7- DSD de profissionais de educação dos diversos níveis 
profissionais de educação dos diversos níveis $\mid$ formação continuada

Fonte: elaboração própria (Utiliza-se os caracteres $(\dashv, \perp, T, F$,$) para representar as relações de$ determinação; o sinal [--] significa sinonímia; o sinal [-]significa antonímia)

Nas relações de linguagem representadas pelo DSD acima, a expressão profissionais de educação dos diversos níveis é determinada por formação continuada o que constitui o sentido que o professor é um profissional que está em constante formação.

As relações de sentido, observadas ao logo da análise deste artigo, nos possibilitam interpretar que as instituições superiores oferecem formação aos professores dos diversos níveis e para profissionais de outras áreas que desejam ser professores ou que já lecionam sem ter formação na área da educação. A partir das relações de reescritura do termo professor, podemos observar que essas relações produzem sentidos de especificação e de enumeração, dado que professor pode ser:1) o profissional para educação básica; 2) o profissional da educação infantil e das séries iniciais do ensino fundamental; 3) o profissional da educação de diversos níveis; 4) aquele profissional de outra área que leciona ou quer lecionar na educação básica e necessita de formação pedagógica. Percebemos, também, a partir das relações de articulação, que as universidades oferecem formação em nível superior ou formação continuada para os professores dos mais variados graus de formação e dos diversos níveis de ensino, o que nos remete ao sentido de que para ser professor é preciso formação específica e constante.

4) Atuação fora da sala de aula

Art. 64. A formação de profissionais de educação para administração, planejamento, inspeção, supervisão e orientação educacional para a educação básica, será feita em cursos de graduação em pedagogia ou em nível de pósgraduação, a critério da instituição de ensino, garantida, nesta formação, a base comum nacional (BRASIL, 1996, grifo nosso).

No art. 64, professor é reescriturado por substituição à expressão profissionais da educação e mantém relações de articulação por coordenação aos termos: “formação, para administração, planejamento, inspeção, supervisão e orientação educacional para 
educação básica", que por sua vez, estão articuladas a: "será feita em cursos de graduação em pedagogia ou em nível de pós-graduação”, que se articula às expressões: “a critério da instituição de ensino, garantida, nesta formação, a base comum nacional”.

Tais relações enunciativas produzem o sentido de que, para exercer atividades administrativas, de supervisão ou de orientação educacional na educação básica, o professor precisa ter formação superior em pedagogia ou pós-graduação, sendo que tal formação garanta a base comum nacional. Essas relações são apresentadas por meio do seguinte DSD:

Quadro 8 - DSD de profissionais da educação

\section{profissionais da educação}

\section{T}

exercício de funções diversas à sala de aula na educação básica

T

formação em pedagogia ou pós-graduação

Fonte: elaboração própria (Utiliza-se os caracteres $(-, \perp, T,-$,$) para representar as relações de$ determinação; o sinal [--] significa sinonímia; o sinal [-]significa antonímia)

No DSD acima, a expressão profissionais da educação é determinada por “exercício de funções diversas à sala de aula na educação básica” que, por sua vez, é determinada por "formação em pedagogia ou pós-graduação". Neste acontecimento as relações de sentido recortam o memorável de professores que assumem outros cargos no ambiente escolar, ao passo em que tais relações projetam uma futuridade interpretativa de que para se ocupar esses cargos é preciso, além da formação inicial, uma formação específica para o exercício dessas funções.

5) Estágio:

Art. 65. A formação docente, exceto para a educação superior, incluirá prática de ensino de, no mínimo, trezentas horas (BRASIL, 1996, grifo nosso).

No Art. 65, professor é reescriturado por substituição pelo termo "docente", produzindo uma sinonímia, enquanto que também está articulado por coordenação à expressão “A formação”, que por seu turno, se articula por coordenação à expressão 
“incluirá prática de ensino, de no mínimo, trezentas horas”. A expressão “exceto para a educação superior" mantém uma relação de articulação por incidência coma expressão A formação, o que estabelece uma ressalva neste enunciado. Essas relações nos levam à interpretação de que para se formar um professor é necessário que se tenha, no mínimo, trezentas horas de prática de ensino. No entanto, a ressalva estabelecida pela articulação por incidência da expressão "exceto para a educação superior"significa que essa carga horária não se aplica à formação de professores da educação superior. Essas relações de sentido podem ser demonstradas por meio do DSD abaixo:

Quadro 9- DSD de docente

docente - formação para atuar na educação básica - estágio de trezentas horas

Fonte: elaboração própria (Utiliza-se os caracteres $(-, \perp, T,+$,$) para representar as relações de$ determinação; o sinal [--] significa sinonímia; o sinal [-]significa antonímia)

Neste DSD, docente é determinado por “formação para atuar na educação básica” que é determinado por estágio de trezentas horas. Essas relações instauram o sentido de que é necessária uma carga horária de trezentas horas de estágio na formação de um professor para lecionar na educação básica.

6) Exercício do magistério superior

Art. 66. A preparação para o exercício do magistério superior far-se-á em nível de pós-graduação, prioritariamente em programas de mestrado e doutorado. Parágrafo único. O notório saber, reconhecido por universidade com curso de doutorado em área afim, poderá suprir a existência de título acadêmico(BRASIL, 1996, grifo nosso).

No Art. 66, Professor é reescriturado por expansão pela expressão "exercício do magistério superior", o que instaura sentidos de especificação da palavra professor, pois nesse caso, o artigo vai tratar de questões relacionadas ao professor que leciona na educação superior. Essa reescritura está relacionada por meio de articulação por coordenação à expressão "A preparação para o exercício", enquanto que esta se articula, também, por coordenação à expressão: "far-se-á em nível de pós-graduação, prioritariamente em programas de mestrado e doutorado”. Essas relações enunciativas 
instauram sentidos de que, para lecionar na educação superior, o professor deverá ter formação, prioritariamente, em nível de mestrado e doutorado. Vejamos essas relações de sentido no DSD subsequente:

Quadro 10 - DSD exercício do magistério superior

exercício do magistério superior | pós-graduação

Fonte: elaboração própria (Utiliza-se os caracteres $(-, \perp, T,-$, , para representar as relações de determinação; o sinal [--] significa sinonímia; o sinal [-]significa antonímia).

No DSD acima, exercício do magistério superior é determinado por pós-graduação, o que remete ao sentido de que para ser professor nas instituições de educação superior é preciso ter pós-graduação. Nota-se, contudo, que o termo “prioritariamente" está articulado por incidência à expressão "programas de mestrado e doutorado”, ou seja, possuir título de mestre ou doutor não é uma condição obrigatória para lecionar no ensino superior.

Podemos, então, observar o sentindo de não obrigatoriedade de pós-graduação sendo sustentado pelo parágrafo único contido no artigo. A expressão "notório saber" é uma reescritura por substituição que produz uma especificação de sentidos que remetem a alguém que não tem formação específica para professor e mantém relações de articulação por coordenação com a expressão "reconhecido por universidade com curso de doutorado em área afim, poderá suprir a existência de título acadêmico”,o que permite interpretar que o título acadêmico pode ser dispensado quando o notório saber tem reconhecimento de instituição de nível superior que possua prerrogativas para tal.

As relações enunciativas observadas na análise abrem a possibilidade interpretativa de que o notório saber é um conjunto de saberes práticos de alguém que não tem formação específica para exercer o magistério superior, que, no entanto, pode ministrar aulas nesse nível de ensino se tais saberes forem reconhecidos pela instituição universitária. Sendo assim, constituem-se sentidos de que é possível atuar como professor na educação superior sem título acadêmico, desde que sejam cumpridas as exigências especificadas no artigo da lei em questão. 
Nesse acontecimento também é observado um embate de sentidos sobre a formação de professores, pois ao passo que a LDB prioriza a pós-graduação como formação para professores universitários, permite que a prática supere a formação acadêmica no caso do notório saber. Esse embate recorta um memorável tecnicista ao sobrepor o saber prático sobre o acadêmico e projeta a interpretação de desvalorização da profissão docente, uma vez que para ser professor universitário não se exige diploma de curso específico desde que o saber prático seja reconhecido por instituição competente para tal.

7) Valorização dos profissionais da educação:

Art. 67. Os sistemas de ensino promoverão a valorização dos profissionais da educação, assegurando-lhes, inclusive nos termos dos estatutos e dos planos de carreira do magistério público:

I - ingresso exclusivamente por concurso público de provas e títulos;

II - aperfeiçoamento profissional continuado, inclusive com licenciamento periódico remunerado para esse fim;

III - piso salarial profissional;

IV - progressão funcional baseada na titulação ou habilitação, e na avaliação do desempenho;

$\mathrm{V}$ - período reservado a estudos, planejamento e avaliação, incluído na carga de trabalho;

VI - condições adequadas de trabalho. Parágrafo único. A experiência docente é pré-requisito para o exercício profissional de quaisquer outras funções de magistérios, nos termos das normas de cada sistema de ensino(BRASIL, 1996, grifo nosso).

No Art. 67, Professor é reescriturado por substituição pelo termo profissionais da educação e, assim, produz relações de especificação e definição, ou seja, especifica o tipo de profissional que será contemplado pelo artigo em questão, no caso, o professor, ao mesmo tempo em que define, uma vez que professor é um profissional da educação. Tal reescritura mantém relações de articulação por coordenação à expressão “Os sistemas de ensino promoverão a valorização”, enquanto que esta expressão se articula à expressão "assegurando-lhes, inclusive nos termos dos estatutos e dos planos de carreira do magistério público", visto que no termo "assegurando-lhes", o pronome "lhes" é uma reescritura por condensação de professor. Tais relações estabelecem o sentido de que a valorização do professor será promovida pelos sistemas de ensino e que essa valorização considerará os termos do estatuto dos planos de carreira. Podemos representar essas relações de sentido no DSD seguinte: 
Quadro 11 - DSD de profissionais da educação

profissionais da educação - valorização - sistemas de ensino

Fonte: elaboração própria (Utiliza-se os caracteres $(-, \perp, T,+$,$) para representar as relações de$ determinação; o sinal [--] significa sinonímia; o sinal [-] significa antonímia).

No DSD desenvolvido acima, o termo profissionais da educação é determinado por valorização, sendo este último determinado por sistemas de ensino, isto é, a valorização dos profissionais da educação compete aos sistemas de ensino.

Para dar continuidade à análise da construção de sentidos de professor, se faz pertinente que observemos quais sentidos de valorização são constituídos ao longo do artigo. Na sequência, são elencados alguns elementos que compõem aquilo que a lei determina como valorização profissional, e, ao analisarmos as relações de linguagem contidas neste acontecimento enunciativo, nota-se que o termo valorização é reescriturado por expansão pelas expressões: “ingresso exclusivamente por concurso público de provas e títulos; aperfeiçoamento profissional continuado; piso salarial profissional; progressão funcional; período reservado a estudos, planejamento e avaliação, incluído na carga de trabalho e condições adequadas de trabalho”. Essas reescrituras além de expandir os sentidos de valorização do professor, instauram sentidos de especificação e definição ao caracterizar diversos elementos distintos, ao passo que também produzem uma enumeração ao elencar todos esses elementos. Seguimos assim, com a representação dessas relações por meio do DSD abaixo:

$$
\text { Quadro } 12 \text { - DSD de valorização }
$$

piso salarial profissional e condições de trabalho adequadas

$\perp$

formação continuada- valorização $\quad$-concurso público de provas e títulos $T$

tempo para avaliação, planejamento e estudo

Fonte: elaboração própria (Utiliza-se os caracteres $(-, \perp, \top, F$, ) para representar as relações de determinação; o sinal [--] significa sinonímia; o sinal [-]significa antonímia) 
Neste DSD, valorização é determinada pelas expressões: Formação continuada, concurso público de provas e títulos, condições adequadas de trabalho, piso salarial profissional e tempo para avaliação, planejamento e estudo. Essas relações enunciativas recortam o memorável de sentidos sobre a valorização profissional do professor que envolve diversas questões como, por exemplo, o direito a um piso salarial profissional, a estabilidade na carreira via concurso público, formação continuada, plano de carreira, tempo para planejamento e outras atividades profissionais extraclasse que não extrapolem a carga horária, entre outras questões.

Ao final do excerto, no parágrafo único, o termo "experiência docente" é uma reescritura por expansão que instaura um desenvolvimento do sentido de professor, visto que podemos reescrever experiência docente por ministrar aulas. Essa reescritura mantém relações de articulação por dependência com é pré-requisito que, por sua vez, se articula por coordenação à "para o exercício profissional de quaisquer outras funções de magistérios", isto é, experiência docente é condição para exercer profissionalmente as funções de magistérios, no caso, no artigo é citado magistério público ou quaisquer outras funções de magistérios. Vejamos o DSD abaixo:

Quadro 13 - DSD de professor

professor $\nmid$ magistério

Fonte: elaboração própria (Utiliza-se os caracteres $(-, \perp, \top, F$, ) para representar as relações de determinação; o sinal [--] significa sinonímia; o sinal [-] significa antonímia)

No DSD acima, professor determina magistério. Este acontecimento nos permite interpretar que ser professor é a condição para o exercício do magistério uma vez que professor é o profissional que ministra aulas. Sendo assim, ao longo da análise, constituem-se sentidos de professor como um profissional amparado por uma série de leis que garantem a promoção de sua valorização profissional e que ser professor é a condição fundamental para o exercício dos diversos tipos de magistério.

\section{Considerações finais}


A SA parte da premissa de que os sentidos se dão no acontecimento de linguagem, sendo que cada acontecimento é único. Portanto, os sentidos não são fixos. A enunciação, enquanto acontecimento do funcionamento da língua consiste numa relação entre língua e sujeito, não obstante, vimos que esta relação é uma prática política, dado que o político para nosso escopo teórico se caracteriza pelo conflito. Isto é, além de não serem fixos ou estanques, os sentidos têm como característica o conflito constante. Em suma, a língua é atravessada pelo político, e este instaura uma disputa incessante pelo direito de falar em uma relação de exclusão e inclusão contínua.

Partindo desses princípios, podemos observar, ao longo da análise realizada neste trabalho, a presença deste conflito de sentidos do termo professor e de sua formação profissional.Nota-se que para atuar na educação básica, o professor deve ter uma formação extensiva, que contemple os objetivos dos níveis e modalidades de ensino e que seja capaz de suprir as demandas de cada fase do desenvolvimento do aluno. Para tanto, o professor necessita de formação em nível superior, em cursos de licenciatura e pode contar com programas de formação continuada, pois o professor é um profissional que deve estar em constante formação. No entanto, embora a educação infantil e as séries iniciais do ensino fundamental façam parte do que a LDB № 9.394 / 96 considera educação básica, para atuar profissionalmente nessas duas etapas basta que o professor possua formação em nível médio. Ainda sobre a formação de professores para a educação básica, há também programas de formação pedagógica para aqueles que possuem formação superior em outra área, mas que lecionam ou pretendem lecionar neste nível de ensino, o que pressupõe a atuação de professores sem formação específica. Já para o professor que atua ou deseja atuar em outras áreas da educação, diferentes das salas de aula, como por exemplo, em áreas administrativas ou orientação educacional se faz necessária formação específica.

No que diz respeito ao professor que leciona no nível superior é prioritário que se tenha título de mestre ou doutor, contudo é permitido o notório saber, ou seja, que professores sem titulação acadêmica atuem nesse nível de ensino, desde que sejam reconhecidos como tal pela instituição de ensino superior. Percebe-seentão que este acontecimento enunciativo instaura sentidos de que a prática supre o diploma e, por conseguinte, sentidos de desvalorização e desprestígio da profissão docente, pois coloca 
em xeque a importância da formação profissional ao passo que se admite professores sem formação para lecionar.

Sendo assim, a corroborar com nossa hipótese, observamos nas análises dos enunciados um embate constante de sentidos no que tange a formação do professor. Há um conflito de sentidos entre formação institucional e não institucional, melhor dizendo, o político se configura na medida em que o professor é um profissional reconhecido e amparado por uma série de leis que regulamentam sua prática, fomentam a formação para o exercício de sua profissão e se admite a importância de uma formação específica para cada área de atuação do professor, no entanto, esses enunciados projetam interpretações de desvalorização e de desprestígio quando a própria lei, que regulamenta a profissão, admite que professores sem formação atuem nos mesmos níveis que o professor especializado, tanto na educação básica como no ensino superior, ou seja, o conflito está instalado no acontecimento de maneira em que a tensão se dá na exigência da formação especializada do profissional enquanto prioridade, ao mesmo tempo em que a formação é posta de lado frente ao notório saber, fator que torna ao mesmo tempo a norma rígida e flexível. Assim,é possível pensar que esses sentidos apontam para certa valorização da prática em detrimento da teoria, o que leva a considerar a formação acadêmica como algo secundário e isso implica diretamente na práxis docente, logo que as consequências podem variar desde desmotivação profissional, desprestígio, desvalorização, precarização da profissão docente, rejeição da procura pela docência como profissão,a desvalorização das pesquisas de pós-graduação e até mesmo o seu desmonte.

\section{Referências}

BENVENISTE, E. Problemas de linguística geral. Tradução de Maria da Glória Novak e Luiza Neri. São Paulo: Ed. da Universidade de São Paulo, v8, 1976.

BRASIL. Ministério de Educação e Cultura. LDB - Lei nº 9394/96, de 20 de dezembro de 1996. Estabelece as diretrizes e bases da Educação Nacional. Brasília: MEC, 1996. 
Ministério de Educação e Cultura. Lei no 12.014/2009, de o6 de agosto de 2009. Altera o art. 61 da Lei no 9.394, de 20 de dezembro de 1996, com a finalidade de discriminar as categorias de trabalhadores que se devem considerar profissionais da educação. Brasília: MEC, 2009.

GUIMARÃES, E. Semântica do Acontecimento. Campinas-SP: Pontes. 2002. . A palavra: Forma e Sentido. Pontes. Campinas, 2007. A enumeração: funcionamento enunciativo e sentido. Cadernos de Estudos Linguísticos, Campinas, v. 51, n. 1, p. 49-68, 2009.

. Análise de texto: procedimentos, análises, ensino. Campinas, SP: Editora RG, 2011. . Semântica: enunciação e sentido. Campinas-SP: Pontes, 2018.

CONCLI, Raphael. Após 20 anos, LDB não trouxe avanço pleno para educação no Brasil. In: Jornal da USP. 31/o1/2017. Disponível em: <jornal.usp.br/?p=65899>. Acesso em: 20 de jun. 2019.

LAGAZZI, S. O recorte significante na memória. Apresentação no III SEAD -Seminário de Estudos em Análise do Discurso, UFRGS, Porto Alegre, 2007. In: O Discurso na Contemporaneidade. Materialidades e Fronteiras. INDURSKY, F.,FERREIRA, M. C. L. \& MITTMANN, S. (orgs.). São Carlos, Claraluz, 2009.

ORLANDI, Eni P. Língua e conhecimento linguístico: para uma história das ideias no Brasil. São Paulo: Cortez, 2002.

Recebido em 30/o6/2019. Aprovado em 22/12/2019. 